RESENHA

\title{
Prática linguisticamente apropriada: uma abordagem que orienta professores a educar crianças bilíngues
}

\author{
Mayara Priscila Reis da Costa'
}

CHUMAK-HORBATSCH, R. Linguistically appropriate practice: a guide for working with young immigrant children. Toronto: University of Toronto Press, 2012.

Ao submeter uma proposta de investigação sobre a construção de um modelo pedagógico para crianças indígenas nas escolas urbanas da Amazônia brasileira (Oiapoque, Amapá), tive a oportunidade de ler a obra Linguistically appropriate practice, ou Prática linguisticamente apropriada (tradução nossa), publicada pela University of Toronto Press em 2012. A autoria desse livro é de Roma Chumak-Horbastch, professora da Universidade Ryerson (Toronto, Canadá) que se dedica à área da pedagogia multilíngue, especialmente às necessidades únicas de linguagem e alfabetização de crianças e jovens bilíngues.

Partindo da premissa de que todas as crianças, quando nascem, são biologicamente iguais, não importando sua origem, cultura ou classe social, excetuando-se os casos particulares, ao crescerem, elas intuem cognitivamente a linguagem da comunidade a que pertencem, interagindo com falantes que são andaimes linguísticos (Bruner, 1983). Por outro lado, crianças que vivenciam dois contextos linguísticos diferentes (casa e escola) acabam por construir duas gramáticas mentais distintas (Chomsky, 1965) e, ao fazerem uso dessas habilidades e experiências na língua de casa juntamente com a língua aprendida na escola, se tornam bilíngues emergentes (em formação) e hoje são a norma no século XXI (García, 2009b, 2014). O interessante aqui é que, ao entrarem na sala de aula, essas crianças percebem que o idioma de casa não é (e nunca será) legítimo na escola ${ }^{1}$.

Diante dessa singularidade, a autora apropria-se do contexto multilíngue e multicultural do Canadá como berço para amadurecimento de sua abordagem. No livro, ela demonstra que $43 \%$ das crianças de Toronto são falantes de pelo menos

1 Isso também ocorre em algumas escolas urbanas brasileiras, onde crianças indígenas convivem diariamente com suas próprias línguas ao mesmo tempo em que aprendem o português. Essa questão particular vem sendo desenvolvida na Amazônia (Reis da Costa, Pereira e Macedo, 2020) com conhecimento da autora do livro.

IInstituto Federal de Educação, Ciência e Tecnologia do Amapá, Oiapoque, AP, Brasil. 
uma língua de herança, isto é, são fluentes na linguagem etnocultural de sua comunidade, que pode ser (ou não) a sua língua materna (Cummins, 1983).

Baseada nisso e em muitos anos de pesquisa e prática pedagógica, a autora desenvolveu o método linguistically appropriate practice (LAP): uma abordagem inovadora, inclusiva e linguisticamente apropriada que orienta professores a educar crianças imigrantes que chegam às escolas com pouca (ou nenhuma) proficiência no idioma da sala de aula e com alguma compreensão de alfabetização. A característica primordial dessa obra é o reconhecimento dos dois mundos linguísticos das crianças (casa e escola), celebrando suas diferenças culturais e potencializando seus múltiplos talentos.

O livro, que inclui referências a Jim Cummins, autor do prefácio, e a Ofelia García, que fornece a base teórica principal, destina-se a profissionais da educação infantil que trabalham com crianças falantes de línguas minoritárias em escolas urbanas e também a interessados nas áreas da pedagogia e alfabetização multilíngue/ bilíngue. Em ambos os casos, o leitor é, muitas vezes, incentivado a refletir sobre sua prática educacional atual e orientado a promover a inclusão das línguas de herança das crianças a fim de melhor prepará-las para a complexidade do século XXI.

Quanto à estrutura, a obra contém introdução, três partes fundamentais e conclusão. A seção introdutória, "The road to linguistically appropriate practice", apresenta um ensaio acadêmico que sustenta o desenvolvimento da abordagem pela autora, descreve brevemente seus sete capítulos, indica orientações de uso e define seus principais termos.

Mais adiante, a parte 1, "Laying the groundwork for LAP", contextualiza a obra. $\mathrm{O}$ capítulo 1 problematiza a presença global de crianças imigrantes em escolas de grandes centros urbanos com base em dados demográficos. Em seguida, o capítulo 2 fornece a ferramenta pedagógica qualitativa language portrait (retrato linguístico), que recolhe informações da diversidade linguística das crianças, suas necessidades duplas de linguagem e alfabetização e situações preocupantes que enfrentam no monolinguismo. Posteriormente a isso, três diferentes abordagens pedagógicas são apresentadas no capítulo 3: assimilativa (sobreposição da língua e cultura majoritária), solidária (reconhecimento da diversidade com restrição das experiências linguísticas e culturais) e inclusiva (inclusão e promoção de várias línguas e culturas). Finaliza-se no capítulo 4 com a exploração do LAP e sua base teórica central: o bilinguismo dinâmico, uma habilidade linguística e comunicativa de navegar em contextos multilíngues e multimodais distintos (García, 2009a). Esse enquadramento relaciona-se com a noção de translinguagens, entendida como a perspectiva individual do falante ao (re)modelar sua própria linguagem, flexibilizando-a e combinando-a em um repertório de possibilidades, práticas, recursos e estilos linguísticos e comunicativos diferentes (Yip e García, 2018).

A segunda parte, "Setting the stage for LAP", ajuda o professor a preparar fisicamente sua própria sala de aula para a adoção do método. O capítulo 5 convida o leitor a experimentar esse método, apresentando suas estratégias de planejamento didático. Entre elas, a criação do language centre (centro de idioma), um ambiente de exploração das línguas pelas crianças, é a mais relevante. Depois disso, o leitor encontra recomendações pedagógicas para acolhimento e acompanhamento de crianças imigrantes dentro e fora de sala no capítulo 6 . 
A seguir, na terceira parte, "Implementing LAP activities", o capítulo 7 baseia-se em três questões essenciais (quem sou eu? quem é você?? quem somos nós?) para ajudar intencionalmente as crianças a se envolverem na construção e na definição de sua identidade e diferença (Hall, 2006). Para isso, descreve mais de 40 atividades e estratégias pedagógicas de fácil implantação sem a exigência de o professor ser fluente no idioma das crianças. Tais atividades estão organizadas nas seguintes temáticas: fazendo um mapa de idiomas de herança; usando idiomas de herança na sala de aula; vinculando a casa e a sala de aula; trazendo o mundo exterior para a sala de aula; e compartilhando livros e jornais com crianças. Ao final de cada uma delas, a autora fornece dicas de ensino e explicação de seus benefícios didáticos.

Por fim, para concluir a obra, o tópico "Looking ahead" ressalta que todas as atividades do LAP podem ser ajustadas para melhor corresponder ao nível de desenvolvimento linguístico e ao grau de interesse das crianças, atendendo a suas peculiaridades, potencialidades e dificuldades e dando-lhes a importância necessária para o sucesso acadêmico.

Com efeito, é notória a riqueza redigida e gentilmente detalhada por $\mathrm{Chu}-$ mak-Horbatsch, que, além de propor uma nova prática pedagógica exitosa com crianças falantes de línguas minoritárias no espaço escolar urbano, se preocupou também com todos os envolvidos no processo delicado da pedagogia multilíngue, dando especial atenção às famílias das crianças. Em linhas gerais, essa obra encoraja os profissionais da educação infantil para a construção, o desenvolvimento e a manutenção de uma plataforma segura de aprendizagem: a sala de aula, um lugar democrático em que todas as crianças possam sentir-se felizes, confiantes e orgulhosas em experimentar, atuar e aceitar o multilinguismo e o multiculturalismo.

Em suma, é pertinente mencionar que o LAP não se encerrou nesse exemplar. No ano de 2019, a autora publicou uma versão ampliada desse método (Chumak-Horbatsch, 2019). Isso quer dizer que ela não só foi capaz de compartilhar as vozes e as experiências de vários profissionais de ensino multilíngue de diferentes países, como também investiu em questões não contempladas nessa análise.

\section{REFERÊNCIAS}

BRUNER, J. Child's talk: learning to use language. Nova York: W. W. Norton \& Company, 1983.

CHOMSKY, N. Aspects of the theory of syntax. Cambridge: MIT Press, 1965.

CHUMAK-HORBATSCH, R. Using linguistically appropriate practice: a guide for teaching multilingual classrooms. Blue Ridge Summit: Multilingual Matters, 2019.

CUMMINS, J. Heritage language education: a literature review. Toronto: Ontario Institute for Studies in Education, 1983.

GARCÍA, O. Education, multilingualism, and translanguaging in the 21st century. In: SKUTNABB-KANGAS, T. et al. (org.). Multicultural education for social justice: globalizing the local. Bristol: Multilingual Matters, 2009a. p. 140-168. 
GARCÍA, O. Emergent bilinguals and TESOL: what's in a name? TESOL Quarterly, v. 43, n. 2, p. 322-326, 2009b. Disponível em: https://doi.org/10.1002/j.1545-7249.2009. tb00172.x. Acesso em: 20 jul. 2020.

GARCÍA, O. Educação, multilinguismo e translanguaging no século XXI. In: MOREIRA, M.; ZEICHNER, K. (org.). Filhos de um Deus menor: diversidade linguística e justiça social na formação de professores. Ramada: Edições Pedago, 2014. p. 53-76.

HALL, S.A identidade cultural na pós-modernidade. 11. ed. Rio de Janeiro: DP\&A, 2006.

REIS DA COSTA, M. P.; PEREIRA, Í. S.; MACEDO, S. L. Initial literacy teaching of indigenous children: designing pedagogy for urban schools. In: NEOKLEOUS, G.; KRULATZ, A.; FARRELLY, R. (org.). Handbook of research on cultivating literacy in diverse and multilingual classrooms. Pensilvânia: IGI Global, 2020. p. 472-494. Disponível em: http://doi.org/10.4018/978-1-7998-2722-1.ch022. Acesso em: 15 jul. 2020.

YIP, J.; GARCÍA, O. Translinguagens: recomendações para educadores. Tradução de Jefferson Virgílio. Revista Iberoamérica Social, v. 9, p. 164-176, 2018. Disponível em: https://repositorio.ul.pt/bitstream/10451/33560/1/ICS_JVirgilio_TRanslinguages_ TRAD.pdf. Acesso em: 10 jul. 2020.

\section{SOBRE A AUTORA}

Mayara Priscila Reis da Costa é doutoranda em ciências da educação, especialidade de literacias e ensino do português pelo Instituto de Educação da Universidade do Minho (Portugal). Professora do Instituto Federal de Educação, Ciência e Tecnologia do Amapá (IFAP).

E-mail: mayara.reis@ifap.edu.br

Recebido em 14 de setembro de 2020 Aprovado em 2 de março de 2021 